\title{
The Use of Technology by Gold Coast Legal Practitioners
}

\section{Lauren Joy Jones}

Australia

\section{Ashley Pearson}

University of the Sunshine Coast, Australia

\begin{abstract}
Digital technology is inexorably changing the landscape of law. From the adoption of sustaining technologies, which enhance the productivity and efficiency of the traditional law firm, to the creation of disruptive technologies, which fundamentally challenge the established forms of the legal profession, the digitalisation of the legal sphere opens up new spaces and structures of legal practice that challenge the form of traditional law firms. Existing literature on the digitalisation of law paints a narrative of technological resistance by traditional law firms, suggesting that BigLaw firms are defensive of the power and status that the current model affords them. However, in reality, the wealth and expanse of BigLaw firms allow them to freely invest in and create new technological innovations. Recent Australian research places BigLaw firms at the forefront of adopting digital technologies into the legal market, leaving behind small and medium-sized legal firms as the victims of digital disruption rather than as technological adopters or beneficiaries.

This article stands in contrast to the literature on traditional small and medium-sized firms, arguing that lawyers from such firms in Australia are not only embracing the use of technology but are also actively engaging in the digital transformation of legal practice. It presents qualitative findings from a 2018 study that involved open-ended interviews with nine lawyers from the Gold Coast, Australia on their use and adoption of digital technologies in their professional legal practice. Through unpacking these findings, this article demonstrates a new perspective of small and medium-sized traditional legal firms in which they do not resist law's digital future but instead embrace it.
\end{abstract}

Keywords: Legal practice; lawyers; digital technology; disruption; innovation.

\section{Introduction}

Digital technology is changing the processes, services and products of legal practice. Legal practitioners stand at a crossroads where they must decide whether to plunge into the new technological world of document automation and algorithmic justice or cling to traditional, tried-and-true manual methods of legal practice.

There is a substantial body of literature in the form of academic books and articles, ${ }^{1}$ research reports from law societies ${ }^{2}$ and news publications that discuss technology's impact on the legal profession. ${ }^{3}$ Many commentators see the use of technology

\footnotetext{
${ }^{1}$ E.g., Kowalski, Great Legal Reformation; Simpson, "Algorithms or Advocacy”; Susskind, End of Lawyers.

${ }^{2}$ E.g., The Law Society of New South Wales, Future of Law; The Law Society of England and Wales, Capturing Technological Innovation; The Canadian Bar Association, Future of Legal Services.

${ }^{3}$ E.g., Kane, "Uberisation of Profession by Technology"; Patty, "Digital Disruption."
}

This work is licensed under a Creative Commons Attribution 4.0 International Licence. As an open access journal, articles are free to use with proper attribution. ISSN: 2652-4074 (Online) 
within the profession as having a positive impact on the legal landscape, ${ }^{4}$ viewing the increased availability of legal information, ${ }^{5}$ consumer accessibility to justice, ${ }^{6}$ the flexibility and efficiency of lawyers ${ }^{7}$ and the affordability of legal services ${ }^{8}$ as strongly beneficial to the wider community. However, not all academics are convinced of technology's positive impact on legal professional practice. Common concerns raised about the use of technology in the legal profession include the automation of work, ordinarily performed by junior lawyers, with algorithms ${ }^{9}$ and the ethical dangers of cloud-based storage systems, email, e-filing and e-service technologies ${ }^{10}$ with respect to a lawyer's duties of confidentiality and privacy. ${ }^{11}$ Whether technological intervention in the legal market is for better or worse, it is undeniable that digital technology is steadily changing the form of traditional legal practice as it is currently structured. ${ }^{12}$

This article addresses a significant gap in the literature about the effects that technology adoption has on legal practice within small and medium-sized law firms. It does so by presenting qualitative research based on semi-structured, open-ended interviews conducted with nine Gold Coast legal practitioners to provide insight into two key research questions:

1. How are Gold Coast legal practitioners currently using technology in their practice?

2. How do Gold Coast legal practitioners see technology impacting their practice in the future?

This article presents its findings in three movements. The first section identifies the unchallenged assumption in the literature that lawyers in smaller traditional firms are less likely to embrace technology and risk being left behind. Drawing on literature on digital disruption within the legal sphere, the second section presents qualitative findings from research conducted in 2018 involving semi-structured, open-ended interviews with nine lawyers from the Gold Coast, Australia that focused on their use and adoption of digital technologies in their professional legal practice. This article unpacks the findings through the thematisation of the key benefits that digital adoption brought these practitioners, contrasted with the challenges and difficulties associated with disruptive technologies. Selected interview excerpts provide insight into how these professionals currently use technology in their practice of law and how they anticipate using technology in the future. Finally, the third section draws on the findings of the study to argue that lawyers from small traditional firms on the Gold Coast are not being disrupted by the advent of technology in the legal profession but are actively engaging in the digital transformation of legal practice instead.

\section{Technological Disruption in the Australian Legal Market}

Technology is, as sometimes described by legal literature, a herald of death for the global legal profession. Foreboding titles such as 'The Death of Big Law'13 and The End of Lawyers? ${ }^{14}$ are employed to evoke a sense of fear and uncertainty about the consequences of technology within the legal sphere. The belief that technology heralds a 'death' or 'end' for law, although believed to be grossly exaggerated by some, symbolises an undeniable change within a long static profession. Moving away from the more alarmist terminology of the 'end' or 'death' of law, academic literature has instead adopted the term disruptive as a more nuanced way to describe the way in which technological developments are transforming the legal profession. ${ }^{15}$

The term disruptive, particularly in the context of disruptive innovation as used in the literature on law and technology, was coined by Clayton Christensen as a way to distinguish between the effects of different types of technologies on the market. Christensen draws a vital distinction between sustaining and disruptive technologies. ${ }^{16}$ Sustaining technologies are those that sustain and strengthen the way in which a market currently operates, whereas the term disruption is used to describe an

\footnotetext{
${ }^{4}$ Simpson, "Algorithms or Advocacy," 51.

${ }^{5}$ Marcus, "Impact of Computers," 1827.

${ }^{6}$ Susskind, Tomorrow's Lawyers, 93-100.

7 Thornton, "Flexible Cyborg," 9.

${ }^{8}$ Waye, "Innovation," 213.

${ }^{9}$ Smith, "Threat of Ideas," 13; Simpson, "Algorithms or Advocacy," 52. The plight of junior lawyers in a technological world is commonly highlighted in the literature. Michael Smith notes that automation may reduce employment opportunities for junior lawyers. Additionally, Simpson notes that automation may reduce the experience and training such work otherwise brings to a junior lawyer's skill set.

${ }^{10}$ Crews, "E-filing," 82-83.

${ }^{11}$ Crews, "E-filing," 82-85.

${ }^{12}$ Susskind, Tomorrow's Lawyers, 59-61.

${ }^{13}$ Ribstein, "Death of Big Law."

${ }^{14}$ Susskind, End of Lawyers. See also Morgan, Vanishing American Lawyer.

${ }^{15}$ Gillers, "Profession," 955-56.

${ }^{16}$ Christensen, Innovator's Dilemma, 169.
} 
innovation, process or product that changes and challenges the operation of a given market and eventually displaces established competitors. ${ }^{17}$ The concepts of sustaining and disruptive technologies were further developed in a legal context by Richard Susskind, who identified technologies such as document automation, relentless connectivity and project management technologies, among others, to be capable of disrupting the legal profession. These technologies are more than conjecture but, rather, are real technologies that are currently shaping modern legal practice. The research questions at the heart of this study target the impact of both sustaining and disruptive technologies to determine how technology has altered or disrupted the legal practice of Gold Coast solicitors, reflecting the opportunities and challenges that digital technologies bring.

Australia's liberalised regime provides a unique jurisdictional backdrop to the evolving discussion on sustaining and disruptive technologies within professional legal practice. The legislative landscape in Australia is argued to be more responsive in adapting to and enabling technological change than other jurisdictions. ${ }^{18}$ For example, Australia's regulatory regime permits incorporated legal practices, which allows firms to be publicly traded as well as owned and operated by those without legal training, albeit with at least one legal practitioner director. ${ }^{19}$ The Legal Profession Act 2007 (Qld) additionally allows for the creation of multidisciplinary partnerships, which advance opportunities for legal practitioners to collaborate with people in other industries in the delivery of legal services. ${ }^{20}$ Australia's more liberal legal framework is based on the belief that innovation, increased competition and economic efficiency can be further advanced through making the law firm more marketresponsive. ${ }^{21}$ As a result, new skill sets such as retail governance and information technology can be brought into the management of a firm, enabling new ideas to 'disrupt' legal services. ${ }^{22}$ In contrast, law firms in the US hold a greater monopoly over the legal profession through regulatory prevention of incorporation or collaboration with non-legal parties. ${ }^{23}$

Additionally, Australian law recognises a difference between generic legal documents (which clients can complete) and bespoke, customised documentation. ${ }^{24}$ Customised documentation would be considered engaging in legal practice, therefore needing a qualified person to draft, but generic legal documents can potentially be automated or created by the clients. ${ }^{25}$ While there is no steadfast rule to this distinction, and it is decided on a case-by-case basis as a matter of fact and degree, ${ }^{26}$ allowing the production of legal documents without a lawyer means the Australian market is potentially more prone to disruptive technologies that change the way people access legal services. For these reasons, the Australian legal profession provided an information-rich environment in which to conduct these interviews on the use of technology within legal practice.

\section{Overlooking Technological Adoption in Small- and Medium-Sized Firms}

Much of the literature on the use of technology within legal professional practice overlooks technological adoption within small or medium-sized firms in favour of discussing BigLaw and NewLaw firms. One potential reason for this narrow focus could be the creation of a false dichotomy between BigLaw and NewLaw firms. In explanation of this false dichotomy, we draw on Michael Guihot, who has theorised that the disruption that these new technologies cause in the legal market are not a result of the technology itself, but rather the disruption is 'a reaction to' client dissatisfaction with the trappings of the traditional law firm. ${ }^{27}$ Entrenched and enforced barriers to justice such as the overpriced billing, the information imbalance between lawyer and client, and the general inefficiency of manual labour have long prohibited access to justice for some parties. The use of disruptive technological innovations to overcome these problems not only drives positive change by opening up the legal market to new clients ${ }^{28}$ but also operates as a mode of critique of the traditional law firm structure. ${ }^{29}$ By posing disruptive technologies

\footnotetext{
${ }^{17}$ Christensen, Innovator's Dilemma, 504; Waye, "Innovation."

${ }^{18}$ Christensen, Innovator's Dilemma, 164; Jones, "Reforming Lawyer Mobility."

${ }^{19}$ Kowalski, Great Legal Reformation, 3; Legal Profession Act 2007 (Qld), ch 2.7 div 2.

${ }^{20}$ Legal Profession Act 2007 (Qld), ch 2.7 div 8.

21 Semple, "Taxonomy of Lawyer Regulation," 258.

22 Kowalski, Great Legal Reformation, 10.

23 American Bar Association, Future of Legal Services, 17.

${ }^{24}$ See, e.g., Legal Practice Board v Giraudo [2010] WASC 4, [12]; Australian Competition and Consumer Commission v Murray (2002)

121 FCR 428, [93]-[94]; Cornall v Nagle [1995] 2 VR 188, 204-5; Barristers' Board v Marbellup Nominees Pty Ltd [1984] WAR 335. All cases cited in Waye, "Innovation," 221.

25 The commodification of generic legal documents through automation may hold some problems for law societies and the Legal Services

Commissioner as distancing lawyers from legal documents may result in unsatisfactory work being produced.

26 Waye, "Innovation," 221

27 Guihot, "New Technology," 411 (emphasis in original).

${ }^{28}$ Guihot, "New Technology," 444.

${ }^{29}$ Guihot, "New Technology," 405-6.
} 
as a critique of the common exploitative practices of traditional law firms, the perception that firms must be either traditional (technologically fearful) or innovative (technologically adaptive) is a false dichotomy that has nonetheless attracted much scholarly attention. ${ }^{30}$

\section{The Perception of BigLaw as Technologically Resistant}

BigLaw providers are leading law firms that benefit clients through their notable reputation and increased efficiency due to pooled knowledge and secretarial resources. ${ }^{31}$ One stream of literature has characterised traditional firms (and particularly BigLaw firms as the greatest benefactors of traditional legal practice) as resistant to change ${ }^{32}$ and bound by tradition. ${ }^{33}$ These larger, traditional firms are often painted as eager to maintain their monopoly of power, status and wealthy clientele by refusing to adapt technology that will alter the status quo of the legal profession. ${ }^{34}$

This perception of technological reticence has been influenced by Christensen's 'technology mudslide' theory, which reasons that industry leaders fail in the face of evolving markets due to becoming passive, arrogant, risk-averse or unable to keep up with the rate of technological change. ${ }^{35}$ Moreover, Christensen found that when traditional firms were actively developing or incorporating new technologies, these technologies were sustaining rather than disruptive technologies. ${ }^{36}$ The creation of sustaining technologies defends the power and profit aligned with the traditional law firm model, ${ }^{37}$ allowing incumbent firms to continue to serve high-value customers while preventing emerging traditional law firms from gaining a foothold in the current market. ${ }^{38}$ However, under Christensen's model, new entrants into the market who innovate and use disruptive technologies will almost always eventually displace established competitors as clients begin to favour the disruptive service resulting in the socalled death of BigLaw firms. ${ }^{39}$

However, in stark contrast to the technological 'death' of traditional and BigLaw firms that some of the literature favours, recent studies have found BigLaw firms to be more technologically innovative than their smaller counterparts both internationally and within Australia. ${ }^{40}$ The injection of technology into the legal market does not "portend anything like the death or end of law, but instead, only a need for reformulation' of traditional legal practice. ${ }^{41}$ This reformulation of the legal profession through technological innovation is a challenge that BigLaw firms are actively tackling head-on, not resisting or rejecting, as has been previously asserted. BigLaw firms are theorised to be better positioned to create disruptive technologies than small or medium-sized firms because they have a generous financial buffer that allows them to experiment with new markets and technologies while continuing to profit from the traditional legal model. ${ }^{42}$ A study conducted by Macquarie Bank in 2017 found that 100 per cent of high-profit firms in Australia were using and investing in new technologies. ${ }^{43}$ Furthermore, in researching the technological innovations of the Australian legal profession, Vicki Waye, Martie-Louise Verreynne and Jane Knowler established that larger firms were overall more innovative than smaller Australian firms. ${ }^{44}$ They found that large law firms not only produced quantitatively more innovative products and processes but also produced a greater diversity of innovation. ${ }^{45}$ For example, Corrs Chamber Westgarth has partnered with the machine intelligence analysis company, Beagle, whose software reads contracts then extracts and presents key clauses around responsibilities or termination. ${ }^{46}$ Norton Rose Fulbright has partnered with LawPath to provide fixed-price packages online including time with a senior lawyer to tailor

\footnotetext{
${ }^{30}$ Kronblad, "Beyond Digital Inventions," 124-25.

${ }^{31}$ Examples of Australian BigLaw firms include Clayton Utz, MinterEllison, Herbert Smith Freehills, Allens Linklaters, Ashurst, King \& Wood Mallesons, among others.

${ }^{32}$ Susskind, Tomorrow's Lawyers, 59-61.

${ }^{33}$ Simpson, "Algorithms or Advocacy," 50.

${ }^{34}$ Simpson, "Algorithms or Advocacy," 51.

${ }^{35}$ Christensen, Innovator's Dilemma, 571.

${ }^{36}$ Christensen, Innovator's Dilemma, 571.

${ }^{37}$ Kronblad, "Beyond Digital Inventions," 137. See also Pasmore, Leading Continuous Change.

${ }^{38}$ Dolin, "Adaptive Innovation," 1.

${ }^{39}$ Christensen, "Disruptive Innovation."

40 Waye, "Innovation," 213; Love, "Openness," 1448.

${ }^{41}$ Gillers, "Profession," 956 (emphasis in original); see also Simpson, "Algorithms or Advocacy," 51.

${ }^{42}$ Guihot, "New Technology," 39; Dolin, "Adaptive Innovation," 4; Meyer, "Some Have To," 443.

${ }^{43}$ Macquarie Bank, Industry in Transition, 12.

${ }^{44}$ Waye, "Innovation," 226.

${ }^{45}$ Waye, "Innovation," 226.

${ }^{46}$ Corrs Chambers Westgarth, "Corrs Enters Joint Venture."
} 
packages to customers' needs. ${ }^{47}$ Gilbert + Tobin have claimed to have a strong focus on innovation through its ' $\mathrm{g}+\mathrm{t}<\mathrm{i}>$ ' strategy, ${ }^{48}$ with some innovations enabling the firm to reduce the duration of tasks that would normally take 20 hours to only 2 hours. ${ }^{49}$ BigLaw firms have the deep pockets and expansive data sets needed to effectively adopt and innovate new digital technologies, whereas cost and knowledge remain barriers to the incorporation of technology for smaller law firms. ${ }^{50}$

\section{NewLaw as Technologically Innovative}

Placed in opposition to the traditional law firm, or BigLaw firms, are firms with alternative business models such as emerging 'NewLaw' firms. ${ }^{51}$ Typically, NewLaw firms use the increased efficiency, flexibility and alternative pricing structures offered by disruptive technologies to challenge the traditional model of the legal profession. ${ }^{52}$ For example, Australia-based firm Nexus Law Group has developed its own cloud-based model, OpenLaw and OpenLogic, ${ }^{53}$ which enables clients to connect directly with lawyers in a collaborative and transparent way that ultimately delivers better value for the client. ${ }^{54}$ Australian firms and the Australian Government are equally pushing towards digital solutions and paperless offices by using networks such as Property Exchange Australia, which allow parties purchasing a home to complete and transfer documents digitally, transfer money and lodge documents with land registries. While NewLaw firms offer technological alternatives to traditional legal practice, existing traditional firms may find integrating technology into their current business model and client base to be challenging. Despite the increased agility that smaller traditional firms may have in changing their practice style to compete with NewLaw firms, ${ }^{55}$ the lack of resources available to smaller firms can make it difficult to both adopt and innovate new technologies. ${ }^{56}$

With Australian BigLaw firms and NewLaw firms clearly investing in technology, the literature suggests that small to mediumsized traditional firms are being left behind. This assumption persists even though the question of how these smaller firms engage in technology in their day-to-day business has not yet been researched. This article will rectify this gap in the literature, instead asserting that legal practitioners in small to medium-sized firms are keeping pace with the digital march of progress.

\section{The Interviews}

In responding to the established research questions around how Gold Coast legal practitioners use technology and how they see technology impacting on their legal practice in the future, a series of interviews were undertaken with Gold Coast legal practitioners. ${ }^{57}$ The interviews focused on two key research questions:

1. How are Gold Coast legal practitioners currently using technology in their practice?

2. How do Gold Coast legal practitioners see technology impacting their practice in the future?

As briefly explained above, legal practitioners based within Australia were identified as ideal representatives for research on the use of technology in smaller traditional law firms. According to the National Profile of Solicitors 2018 collated by Urbis, 38 per cent were sole practitioners and 15 per cent worked in firms of two to four partners. ${ }^{58}$ Half of all Queensland solicitors were sole practitioners (50 per cent), making this the highest percentage of sole practitioners within all Australian jurisdictions. The Gold Coast was selected because solicitors practising in firms of two to four partners were strongly represented in

\footnotetext{
${ }^{47}$ Smith, "Legal Giant."

${ }^{48}$ Gilbert + Tobin, "Innovation."

49 Papadakis, "G+T Wants to Use Computers."

${ }^{50}$ Macquarie Bank, Industry in Transition, 24.

${ }^{51}$ Williams, "Disruptive Innovation," 5; Beaton, "Who Coined NewLaw?"

${ }^{52}$ Lim, "What is a True NewLaw Firm?"; Reynolds, "Small is the New Big Law," 6.

${ }^{53}$ Nexus Law Group, "OpenLaw."

${ }^{54}$ Hunter Headline, "Nexus Law Group."

${ }^{55}$ Susskind, End of Lawyers, 82.

${ }^{56}$ Waye, "Innovation,” 225-31. See also Hart, "Sustainable Regional Legal Practice,” 253; Susskind, End of Lawyers, 229. Hart and Susskind give contrasting views to Waye that small firms may be able to stay competitive due to their agility in technological adoption.

${ }^{57}$ The interviews ranged from 20 to 60 minutes. Most interviews took place at the respondent's workplace or in a public space. All respondents were provided with the questions and prompts at least 72 hours prior to the interview.

${ }^{58}$ Urbis, National Profile of Solicitors 2018, 3.
} 
Queensland, at 20 per cent, ${ }^{59}$ with 9.89 per cent of employed Gold Coast solicitors working as sole practitioners and 6.73 per cent of employed solicitors working in-house. ${ }^{60}$

\section{Methodology}

The interviews used a semi-structured, open-ended approach. Open-ended interview questions were favoured as, rather than testing preconceived hypotheses, they allowed for unanticipated answers ${ }^{61}$ and allowed respondents to answer in their own words. ${ }^{62}$ The use of semi-structured, open-ended interviews to conduct legal research has also been performed by Margaret Thornton when researching the work-life balance of lawyers ${ }^{63}$ and Trish Mundy when conducting research into rural and regional lawyers. ${ }^{64}$ The research was conducted with the appropriate ethical clearance. ${ }^{65}$ Pseudonyms were used and any information that could identify the individual or their place of work was redacted. Interviews were recorded before being transcribed to paper copies and the recording deleted.

Table 1: Demographics of Respondents

\begin{tabular}{|c|c|}
\hline & Participants \\
\hline Male & 6 \\
\hline Female & 3 \\
\hline $18-25$ & 1 \\
\hline $25-35$ & 2 \\
\hline $35-45$ & 1 \\
\hline $45-55$ & 2 \\
\hline $55+$ & 1 \\
\hline
\end{tabular}

Table 2: Firm-Size of Respondents

\begin{tabular}{|l|c|}
\hline Firm Size & Participants \\
\hline 1 & 1 \\
\hline $2-4$ & 4 \\
\hline $5-10$ & 2 \\
\hline $11-20$ & 1 \\
\hline $21-50$ & 0 \\
\hline $50+$ & 0 \\
\hline Barrister & 1 \\
\hline
\end{tabular}

\footnotetext{
${ }^{59}$ Urbis, National Profile of Solicitors 2018, 28; Urbis, National Profile of Solicitors 2016. At the time this research was conducted, the National Profile of Solicitors 2018 report had not yet been released, and the previous 2016 report showed that Queensland had the highest representation of firms with two to four partners at 36.6 per cent. This figure has subsequently dropped in the 2018 report and it was acknowledged as a limitation in that report that some law societies had been incorrectly recording data on firm size, which may produce some discrepancies with previous reports.

${ }^{60}$ Queensland Law Society (QLS), "Find a Solicitor.” This figure was calculated manually via the QLS website by the authors and was construed narrowly. Descriptions such as 'employed solicitor', 'ILP [incorporated legal practice] Legal Practice Director' etc. were present on the database; however, they were not taken into account in the 9.89 per cent figure. As a result of the limited parameters of this calculation, the figure could potentially be higher due to the diversity of descriptions used by the QLS.

${ }^{61}$ Stoneman, "Exploring Public Discourses," 850.

${ }^{62}$ McLeod, Qualitative Research, 133.

63 Thornton, "Flexible Cyborg," 9.

${ }^{64}$ Mundy, "Engendering Rural Practice," 490.

${ }^{65}$ The research was approved by the Griffith University Human Research Ethics Committee in April 2018 with the GU Ethics Ref No. $2018 / 295$.
} 
The participant pool was limited to members of the Gold Coast legal profession. This was defined as a solicitor or barrister who has a practising certificate issued by the Queensland Law Society or the Bar Association of Queensland, respectively, and practises on the Gold Coast. ${ }^{66}$ Practice areas varied and included a barrister. Respondents took part voluntarily and were invited by either the researchers approaching them personally, or through a general email request sent to the over 300 subscribers of the Gold Coast District Law Association's mailing list. Nine Gold Coast legal practitioners agreed to be interviewed for this research. Due to the small sample size of approximately 3 per cent of all Gold Coast lawyers, this research is predominantly exploratory and does not proport to represent all Gold Coast lawyers. ${ }^{67}$ It does, however, present rich qualitative insights into the experiences of Gold Coast lawyers and their use of technology.

\section{Findings}

There are two dimensions to the findings. The first dimension is the types of technology being adopted by Gold Coast legal practitioners and how these technologies are being used in daily legal practice. The themes of opportunity and challenge emerged from the collective analysis of the respondent's interviews. Key opportunities identified included the benefits of flexible work environments, the automation of document production and easy implementation of alternative billing structures. Challenges included security concerns, job creep, economic efficiency and diminishing skill sets.

The second dimension is the respondents' views on the use of technology in the legal profession and their speculation on the future role of technology within their practice. Generally, all respondents used new technologies within their legal practice, although the depth of engagement varied across the sample. In contrast to the literature on law and technology that suggests practitioners in traditional small to medium-sized firms are reluctant or unable to implement technology into their practice, all respondents in this study reported embracing new technology.

\section{How Are Gold Coast Legal Practitioners Currently Using Technology?}

This section presents the findings in relation to the first dimension of the research conducted in this study. It examines key areas of technology adoption within small and medium-sized Gold Coast legal practices that were identified by the respondents. The findings have a significant focus on practicality, engaging with how the adoption of technology impacts the everyday experiences of each practitioner and their service to clients, and broader changes to the legal field that the adoption of technology portends.

\section{The Opportunities of Practice Management Software and Digital Documentation}

Practice management software was the most prominent, and often the first, technology identified by respondents when asked about the use of technology in their current legal practice. Seven of the respondents used some form of practice management software. ${ }^{68}$ Five of those used cloud-based systems, ${ }^{69}$ while the other two respondents did not have cloud-enabled practice management software. ${ }^{70}$ There was significant diversity as to the specific software used including LEAP, cloud-based LEAP, FilePro and Evolve Practice Management. The use of technologies, such as practice management software or cloud-based storage services, has allowed the respondents to more securely and economically store their files. Another theme identified was the ability to work remotely, which allowed Gold Coast lawyers more flexibility in their work, creating a more satisfying worklife balance for practitioners, as well as having practical and economic benefits for legal practice, albeit at a certain cost or risk.

The respondents drew out several of the immediate practical benefits of practice management software and digital document storage, such as economic efficiency and the security of documents. Seven respondents used some form of technology for document storage: the use of hard drives or cloud-based storage, which were both commonly accessed through practice

\footnotetext{
${ }^{66}$ The QLS and Bar Society of Queensland have the power to grant the practising certificates needed to engage in legal practice as per the Legal Profession Act 2007 (Qld), s 21(1)(a).

${ }^{67}$ Neuman, Social Research Methods, 332-33.

${ }^{68}$ Lawyer A (interview, 19 April 2018); Lawyer B (interview, 21 April 2018); Lawyer C (interview, 3 May 2018); Lawyer D (interview, 4 May 2018); Lawyer E (interview, 9 May 2018); Lawyer F (interview, 11 May 2018); Lawyer G (interview, 18 May 2018); Lawyer I (interview, 5 July 2018).

${ }^{69}$ Lawyer A (interview, 19 April 2018), Lawyer D (interview, 4 May 2018); Lawyer F (interview, 11 May 2018); Lawyer G (interview, 18 May 2018); Lawyer I (interview, 5 July 2018).

${ }^{70}$ Lawyer B (interview, 21 April 2018); Lawyer C (interview, 3 May 2018).
} 
management software. Digital document storage enhanced the security and accessibility of a client's documentation, enabling legal professionals to act more efficiently and flexibly without the risks or costs associated with physical storage. That is, digital storage was reported to be more cost-effective and without the risk of damage that comes with paper-based file storage:

External hard drives are cheap in comparison to off-site storage. And they are also easier to protect whereas papers in a box in a storage facility is subject to vermin, fire, water ... those sorts of things can wreck them. So, electronic storage is a big thing for cost, speed and convenience. ${ }^{71}$

Most respondents were able to digitally store documents with the assistance of their practice management software. Generally, respondents who used the cloud-based LEAP were more positive about their experience than those using earlier versions of non-cloud enabled LEAP. Lawyer A was extremely enthusiastic about their experience in using a cloud-based practice management software. For them, the software was a one-stop shop for everything a lawyer needed to deal with a file. ${ }^{72}$ Other respondents expressed concern about the early adoption of cloud-based technology, hoping to wait for the software to be at a sufficient standard before investing in the technology, particularly given the increased expense of the cloud-based variant. ${ }^{73}$ John Lambert Jr. has found that technology with higher price tags are perceived as less useful in correlation. ${ }^{74}$ The higher cost of the cloud-based system may impact its perceived usefulness in practice and consequently discourage some firms from using them.

Two respondents were still using paper-based files despite having access to cloud-based practice management software. Lawyer $\mathrm{H}$, who did not use either a practice management software or cloud-based software, was still able to work remotely using a desktop, laptop, tablet or mobile phone with digital document storage. This was achieved through an external server provided by an Australian internet service provider. The reasoning behind the decision to use an external server over other available cloud-based technologies was motivated by privacy and security considerations. Lawyer H noted the influence of the Australian Privacy Act 1988 (Cth), which requires information keepers to notify relevant persons when their information is being taken offshore:

It's important to keep that host in Australia in my mind ... [It] makes it more complex for a legal practice to be telling all of our clients 'we are going to be putting all your private and personal information in a cloud in a server somewhere where we really do not have control of it in a country that we don't even know about'. ${ }^{75}$

No other respondent cited privacy or cybersecurity considerations as influencing their decision to adopt technology. The literature has suggested that the ease with which ethical breaches (such as a lawyer's duty of confidentiality) can take place in a connected digital world has led some to propose that being technologically savvy is a de facto part of being a modern lawyer. ${ }^{76}$ For example, public Wi-Fi could be compromised, emails could easily be sent to the incorrect contact and cloud-based systems entail the lawyer entrusting confidential material with a third party. ${ }^{77}$ Resultantly, it has been suggested that these ethical risks are why some lawyers tend to resist change. ${ }^{78}$ Given some of the emphasis on ethical considerations as a barrier for technological adoption within the literature, the respondents' lack of discussion on the topic was unexpected.

\section{Searchability and Accessibility of Legal Documents}

One of the other commonly cited practical benefits of practice management software and digital document storage was the increased accessibility and searchability of files. The first respondent, Lawyer F, expressed frustration at the inability to easily search through files using Practice Evolve. As a result of the poor searchability, their office was not relying on the system as much as they had anticipated and still used paper files. With an improved search function, the respondent believed that the firm could become completely paperless. In contrast, Lawyer A, who used the cloud-based LEAP software, found that its search function worked well and saved a large amount of time. ${ }^{79}$ The second respondent, Lawyer D, who also continued to use paper-

\footnotetext{
${ }^{71}$ Lawyer H (interview, 13 June 2018).

${ }^{72}$ Lawyer A (interview, 19 April 2018).

${ }^{73}$ Lawyer I (interview, 5 July 2018); Lawyer B (interview, 21 April 2018).

${ }^{74}$ Lambert, "Pursuit of the Elusive Antecedents," 261.

${ }^{75}$ Lawyer H (interview, 13 June 2018).

${ }^{76}$ Crews, "E-filing," 85.

${ }^{77}$ Crews, "E-filing," 85

${ }^{78}$ Crews, "E-filing," 82.

${ }^{79}$ Lawyer A (interview, 19 April 2018).
} 
based files, also used the cloud-based LEAP software. They noted that they could probably operate completely paperless but opted not to out of personal preference. ${ }^{80}$

Lawyer $\mathrm{H}$ also noted the benefits of digital document storage in a court setting:

I've been involved in a trial where, for example, I've taken my laptop to court ... and I'm with a barrister or I'm doing it myself and he says 'look, didn't somebody say something, in one of the documents that we've got, with these words?' Well, I can search it. And how long would that take me in court in a particular moment to find a phrase in many volumes? ... Judges don't have that patience to wait for you. ${ }^{81}$

This was not the only example of technology being used to enhance the ease of work during a trial. The barrister that was interviewed, Lawyer E, required their briefs to be sent as PDFs, ${ }^{82}$ preferably through Dropbox. By using the GoodReader application, the barrister was able to easily create notes, highlight, free draw and make tabs to organise the PDFs, just as one would usually do when annotating paper files. ${ }^{83}$ This respondent's use of Dropbox and GoodReader was encouraged after reading an article published by the NSW Bar Association in $2017 .{ }^{84}$ Adoption of the technology has enabled them to drastically change their practice:

I can freely handwrite on [the PDF]. I can put an arrow to it, I can underline stuff, I can highlight it. I can do everything you can do with a normal pen.

... some solicitors don't send you an index, which is a pain ... what I can then do is download the one PDF, but for each document that is in there I can just make a bookmark and I date it. I actually date it in reverse. In that way, all of the documents ... will then be in chronological form. ${ }^{85}$

By using cloud technology, virtual secretaries, Dropbox, GoodReader and a digital signing software called Secure Signing, the respondent has inventively developed their own system for creating their own paperless chambers, despite not using a singular practice management software for barristers.

The adoption of digital documentation has expedited the access and navigation of complex and voluminous legal documentation. This has enabled adopters to spend their time more efficiently-beneficial for both clients and firms-and liberated some of the geographical and physical constraints on legal practitioners that come with paper-based offices.

\section{Technological Efficiency in Document Production}

Document production involves the creation of documents relevant to a client's case. Most respondents used technology to make this process more efficient in both time and cost. However, there were some contradictions between respondents as to the most effective method. In the sample, the technologies used for document production differed between respondents.

Lawyer G's firm had the most extreme adoption of document production technology. As a result of the firm's adoption of an automated document production process, the firm operated with a vastly different business model than that of a traditional law firm. In Lawyer G's firm, documents were produced in 30 seconds, and they operated on a fixed-fee model rather than the more traditional approach of billing for 10 hours of a lawyer's time to create the documents. This technology enabled the firm to scale up and offer fixed-price solutions to clients with no cap placed on the revenue these automated documents earn.

Other respondents also adopted technology for document production that used more typical methods of dictation, templates, secretaries or Legal Process Outsourcing (LPO) to expedite their documents. Six respondents typed and created their own

\footnotetext{
${ }^{80}$ Lawyer D (interview, 4 May 2018).

${ }^{81}$ Lawyer H (interview, 13 June 2018).

${ }^{82}$ Lawyer E (interview, 9 May 2018).

${ }^{83}$ Lawyer E (interview, 9 May 2018).

${ }^{84}$ Taylor, "Paperless Barrister," 48.

${ }^{85}$ Lawyer E (interview, 9 May 2018).
} 
documents, ${ }^{86}$ with three using templates and word processing through their practice management software ${ }^{87}$ Two respondents used dictation machines and sent their transcriptions to their word-processing (WP) staff or secretary. Another used a virtual secretary to dictate and type, and two of the three that used WP staff also used speech recognition software. Lawyer G also used LPO services to outsource legal work to lawyers in other countries. ${ }^{88}$ The main advantages of LPO are said to be time and cost, ${ }^{89}$ yet Lawyer $\mathrm{F}$ found that the quality of outsourced work was consistently lacking and was resultantly concerned about customer satisfaction. ${ }^{90}$ As a result, all work was now done within the firm. Lawyer G continues to use LPO and has one select overseas lawyer that they engage.

Five of the seven respondents that used practice management software in their ordinary legal practice also used the software for document production. Lawyer A, a more junior lawyer, believed that using the practice management document templates had helped them become a better lawyer:

By reading it every day you get in a habit of saying particular words or paragraphs ... you are seeing the way it should be, perfectly structured, all the time because it is built into the template. ${ }^{91}$

The ease and speed of document production using the document production software enabled all the solicitors in Lawyer D's and Lawyer I's firms to do their own typing, with no need for a WP employee. ${ }^{92}$ Lawyer D did not see WP typists as efficient or cost-effective since the document bounced between the lawyer and secretary, and back to the lawyer for double-checking and to make corrections. ${ }^{93}$

In contrast to the others, Lawyer E, a barrister, believed that it was not economical to have lawyers do their own typing, stating, 'because of the rates that I charge, I am the most expensive typist there is. And I just think that is outrageous to put that on to the client. ${ }^{94}$ Instead, Lawyer E employed a virtual secretary to complete their work, although noted that the disadvantages of using a virtual secretary included not being able to push urgent work ahead of other work the virtual secretary had. Nevertheless, through a combination of the virtual secretary and dictation software, Lawyer E's virtual chambers worked well, and with the removal of traditional secretarial staff fees, ultimately ended up as a more cost-effective business model.

The use of dictation technology was present within the sample. Four respondents had used Dragon Dictate over their careers. This software can recognise speech and transcribe it into a Microsoft Word document. Two respondents were still using the software at the time of the interviews. One, Lawyer C, uses Dragon Dictate when their WP is busy with other transcriptions. Lawyer E had found that the program understood context quite well, stating that it was accurate around 95 per cent of the time. On the other hand, Lawyer F found that the amount of software voice-training involved and the number of inaccuracies with voice recognition software meant lawyers were having to manually correct their mistakes anyway.

With the use of technology, document production can be done faster and more conveniently. While there was not one predominant method, the respondents reported taking advantage of word processing and templates, automation, dictation devices and speech recognition software to improve efficiencies and firm profitability.

\section{The Use of Technology to Achieve Increased Flexibility and Mobility in Legal Practice}

The ability to work remotely was identified as being particularly beneficial for sole practitioners and small to medium-sized firms. In a small firm, where there may be only two or three solicitors, cloud technology can allow files to be managed and accessed when a lawyer is sick. For sole practitioners, the increased mobility of cloud-based practice management software and digital file storage enabled sole practitioners to take time off due to illness or a much-needed holiday:

\footnotetext{
${ }^{86}$ Lawyer A (interview, 19 April 2018); Lawyer B (interview, 21 April 2018); Lawyer D (interview, 4 May 2018); Lawyer E (interview, 9 May 2018); Lawyer H (interview, 13 June 2018); Lawyer I (interview, 5 July 2018).

${ }^{87}$ Lawyer A (interview, 19 April 2018); Lawyer B (interview, 21 April 2018); Lawyer D (interview, 4 May 2018 ).

${ }^{88}$ Bennett, "Ethics of Legal Outsourcing," 479.

${ }^{89}$ Shepherd, "Legal Process Outsourcing."

${ }^{90}$ Lawyer F (interview, 11 May 2018).

${ }^{91}$ Lawyer A (interview, 19 April 2018).

${ }^{92}$ Lawyer D (interview, 4 May 2018); Lawyer I (interview, 5 July 2018).

${ }^{93}$ Lawyer D (interview, 4 May 2018).

${ }^{94}$ Lawyer E (interview, 9 May 2018).
} 
One good thing though with technology is you can be anywhere, so even if you're in hospital, then you can have your phone pinging at you. But is that a good thing? Maybe. ${ }^{95}$

Lawyer $\mathrm{G}$ was able to completely change their working environment by using technology to transcend geographical boundaries. The respondent described their working environment and mindset in the lead up to the change:

I worked 14 hours a day. I ate every meal at my desk ... I really loved it for a while ... But I got to a point where I realised I'm just stressed all the time: I'm really negative and critical.

I wanted to live by the beach. And I was like how? I'd have to give up my career.

After changing to a firm that was built around cloud-based technology and automation, Lawyer G was able to move to the Gold Coast permanently without prior approval. ${ }^{96}$ They reported that they had achieved a desirable work-life balance while still working in their niche area of law, with clients based all over the country, and relied on digital technology every day to communicate with the rest of the firm, who also worked remotely. ${ }^{97}$

\section{Using Technology to Integrate Alternative Billing Structures into Legal Practice}

Respondents who used practice management software explained that the technology enhanced their efficiency not only through streamlining their workflow but also through the usefulness of secondary features embedded within the software such as automated time billing, facilitation of legal research and document production using templates that plug into common WP and office suites. $^{98}$

The ease with which practice management systems are able to track and produce bills was highlighted by numerous respondents. Lawyer A considered the tracking of time sheets and the ability to do legal research easily through the system as major advantages. ${ }^{99}$ For Lawyer C, who did not have a fully automated billing system, the semi-automated process was still considered faster than traditional means, which ultimately benefitted the business:

It enables me to do a job faster and then bill it very quickly. There's no point in being in business as a lawyer producing a file and then just letting it sit there and not billing. ${ }^{100}$

Lawyer D, who identified as a principal lawyer, was able to use the automated tracking of billables to more effectively quote fixed-price fees. The respondent regarded the software's facilitation of the ability to provide a profitable fixed price as linked to client care:

In regards of doing the fixed fee, it was easy to create fixed-fee packages because of the [practice management] reports. I can work out exactly how much time it costs for someone to do a certain task and we can do a fixed fee around it. ${ }^{101}$

Two respondents offered fixed-price services to clients while all others worked solely on a time-billing basis. The use of practice management software to calculate fixed-fee alternatives substantiates Susskind's theory that fixed-fee arrangements are a repackaging of the current high fees of time billing, because the fixed prices are based on what a time-billing model would ordinarily charge. ${ }^{102}$ Nevertheless, the combination of working more efficiently through technology and creating alternative fee arrangements can somewhat reduce costs to clients. ${ }^{103}$ These findings show that some Gold Coast lawyers are looking to alternative fee arrangements, and practice management software can assist firms in attaining this.

\footnotetext{
${ }^{95}$ Lawyer I (interview, 5 July 2018).

${ }^{96}$ Lawyer G (interview, 18 May 2018).

${ }^{97}$ Lawyer G (interview, 18 May 2018).

${ }^{98}$ Hathaway, "Practice Management Software," 46.

${ }^{99}$ Lawyer A (interview, 19 April 2018).

${ }^{100}$ Lawyer C (interview, 3 May 2018).

${ }^{101}$ Lawyer D (interview, 4 May 2018).

${ }^{102}$ Susskind, Tomorrow's Lawyers, 20.

${ }^{103}$ Susskind, Tomorrow's Lawyers, 20. According to Susskind, alternative fee arrangements can reduce fees by approximately 10 per cent.
} 


\section{How Do Gold Coast Legal Practitioners See Technology Impacting Their Practice in the Future?}

The second dimension of the study's findings relates to how Gold Coast legal practitioners speculate technology will impact their practice in the future. In answering this question, this section first highlights the attitudes and experiences of respondents with technology in their legal practice. By identifying praise or reluctance for technological adoption as it is currently used in practice, their answers regarding the future adoption of technology are more clearly contextualised.

\section{Relentless Connectivity}

Two of the respondents saw the relentless connectivity of technology as a way to eschew geographical and jurisdictional boundaries. For them, technology promises the opening of new cross-jurisdictional markets where they will be able to advise clients in other states and territories. Their market would no longer be restricted to their local Gold Coast area and this was an exciting prospect for them. Conversely, respondents noted that the increased mobility through technology, which allowed them to maintain their professional work on the Gold Coast while travelling overseas, was an advantage. Lawyer H recounted their ability to go on a cruise and still do necessary work while in the middle of the ocean. Another respondent, Lawyer I, concurred, noting that it was now commonplace for lawyers to be overseas yet able to maintain their ordinary work output.

One concern with the relentless connectivity of technology was the notion of 'job creep', where technology enables work to creep into one's personal hours since digital technologies enable people to be constantly connected to employers and clients in ways not previously possible. ${ }^{104}$ The notion of technology as a cause of job creep was rebutted by two senior lawyers, who believed that not being able to 'switch off' was a result of being a professional as opposed to being an employee in another industry. ${ }^{105}$ For Lawyer $\mathrm{H}$ and Lawyer I, technology was not the cause of difficulties in switching off, but, rather, being a professional and a senior lawyer was the cause. For these lawyers, technology simply gives them the freedom to provide a service from anywhere; they are no longer bound to a desk in an office.

With the instant sending and receiving of emails, clients were reported to be more expectant of an instant response. As Thornton notes, this generates great pressure on the professional. ${ }^{106}$ Managing these client expectations was said to be part of the art of being an effective professional. Lawyer $\mathrm{H}$ stated that when they are unable to immediately attend to a client request, communication is key. For this lawyer, managing client expectations was a part of being an effective lawyer. The speed of communication has changed, so direct and honest communication is key to managing expectations on when work will be completed.

Lawyer G and Lawyer E, who used technology to permanently work remotely, noted difficulties around their professional images in the eyes of other lawyers. They both noted that it was common for other solicitors to not take them seriously once it was revealed they did not have a physical office:

There's a lot of traditional law firms that just don't even get it. The first thing they ask you when you're a lawyer is 'where is your office?'107

These same attitudes were also experienced by the barrister, Lawyer E:

I think in some parts, or in the older parts of the legal community anyway, unless you've got a physical office and unless you've got a physical line and unless you've got a secretary, then you know, you are a bit of a fly-by-nightery. ${ }^{108}$

To overcome this, Lawyer E had used digital office technology from their phone provider to connect a landline to their mobile phone. By providing a landline number, solicitors were more likely to view them as professionals of good rapport. Lawyer G does believe that having a virtual office will become more accepted by other practitioners in the future.

\footnotetext{
104 Thornton, "Flexible Cyborg," 9.

${ }^{105}$ Lawyer H (interview, 13 June 2018); Lawyer I (interview, 5 July 2018).

106 Thornton, "Flexible Cyborg," 14.

${ }^{107}$ Lawyer G (interview, 18 May 2018).

${ }^{108}$ Lawyer E (interview, 9 May 2018).
} 


\section{Robotic Redundancies}

All respondents in the sample expressed a view that technology did not pose a serious risk to lawyers becoming redundant, although some lawyers expressed concerns that junior lawyers would struggle to build the basic practical skills that older lawyers were exposed to as clerks. ${ }^{109}$ Lawyer A, a junior lawyer, was not worried about the future, noting that someone needed to operate the systems and check outgoing work. ${ }^{110}$ One respondent also aired concerns about technology going unchecked. In attempts to heighten profitability by automating document creation, law firms run the risk of leaving errors in the documents as they are no longer being checked by a lawyer. ${ }^{111}$ Lawyer I noted that the technology was not yet sophisticated enough to completely replace incoming graduates:

At the end of the day, I haven't seen a good software system that can draft something the way that a client wants it to be drafted. Those are English skills, those are thought skills, they're bringing ... it all in and dealing with it in a way that a client will say 'I want you to draft it, but I don't want you to be too aggressive'. I don't know how you would explain that to an AI. ${ }^{112}$

Lawyer E, the barrister, also held the view that technology would not render barristers redundant. The more efficiently barristers can conduct their work, the less likely they are to become obsolete and the more apparent the need for special advocacy in legal practice. The general consensus between respondents was that technology will assist lawyers to become more efficient, rather than render them redundant as there are interpersonal aspects of legal practice that cannot be easily replaced by an algorithm.

\section{Technological Adoption and Innovation}

All nine respondents reported they will be embracing technology in legal practice moving forward. Four respondents indicated that, although they consider themselves embracing of technology, they would prefer to adopt tried-and-tested technologies rather than be early adopters. For example, Lawyer $\mathrm{F}$ was hesitant to adopt new technologies as they were an early adopter of a new, disruptive technology that they ultimately found to fail, and also saw this occur with others:

We've seen people that are early adopters, first movers, all that sort of stuff, and they have poured a fair bit of money into something that probably hasn't worked for them at all. ${ }^{113}$

Nevertheless, this respondent still had a positive view on the future and embraced technology once it was tried and tested, noting that embracing technology is important to a law firm's survival.

Notably, two lawyers in the sample were innovating their own disruptive technologies. Both creators of disruptive technologies, Lawyer D and Lawyer G were women. One of these respondents cited that most of the professionals they see innovating are women who are driven by a desire to continue their careers through the flexibility of technology while balancing the duties of motherhood. The idea of women using technology to better balance their career and family lives has been theorised as far back as the 1990s. ${ }^{114}$ Although it was noted that this respondent's experience may not be reflective of the true situation, nevertheless, female Gold Coast legal practitioners are actively innovating new technologies to revolutionise the market.

Lawyer D, a family lawyer, disclosed that they were designing a product that will provide access to a market that does not currently engage with lawyers. With a focus on providing for the needs of those outside of their established market, this innovation could be considered as a disruptive technology based on Christensen's definition. ${ }^{115}$ This lawyer was passionate about providing accessible and affordable legal advice after their own experience of separation. Digital technology provided Lawyer D with a platform to envision and enact their product in the market, disrupting established practice by targeting new clients:

\footnotetext{
${ }^{109}$ Lawyer F (interview, 11 May 2018), Lawyer H (interview, 13 June 2018), Lawyer I (interview, 5 July 2018)

${ }^{110}$ Lawyer A (interview, 19 April 2018).

${ }^{111}$ Lawyer H (interview, 13 June 2018).

112 Lawyer I (interview, 5 July 2018).

${ }^{113}$ Lawyer F (interview, 11 May 2018).

${ }^{114}$ Mossman, "Lawyers and Family Life," 167.

115 Christensen, Innovator's Dilemma, 601.
} 
The [innovation], it opens up a whole new range of clients. These are not the clients that are coming to the firm. These are the people who are scared to go and hire a lawyer. They are scared the relationship is going to blow up or if they hire a lawyer, a lawyer is going to make it worse. There's a lot of people who rightly can't afford it or are afraid ... So, this type of product is targeting those people. ${ }^{116}$

The second innovative respondent, Lawyer G, was motivated to innovate technology to encourage Australians to use estateplanning services. This technology was likewise considered a disruptive technology because it targeted people that fell beyond the traditional legal market. Rather than targeting end clients, the technology targeted other professionals such as accountants and financial advisors. Lawyer G's approach to future legal practice included closed online communities of professionals. The model was designed to allow a more collaborative approach between professionals.

There were also respondents who, while not able to create their own disruptive processes, platforms or products, were able to engage with established technologies in new ways. One described how they learned to create a website for their own firm and build a computer from scratch that was then used in the office. Similarly, Lawyer E was able to use numerous technologies and platforms to create their own functioning system that ultimately eliminated the need for a bricks-and-mortar office. The associated cost of adopting technology or innovating new technologies is often cited as a barrier for smaller firms. However, these findings show that Gold Coast lawyers were able to use technology and innovate their businesses without large capital outlays. ${ }^{117}$

\section{Discussion}

This study found that Gold Coast legal practitioners, as representatives of small to medium-sized firms, were not being outpaced by the technologically founded NewLaw firms or outplayed by the abundantly resourced BigLaw firms, but instead actively adopting and innovating both sustaining and disruptive technologies. The findings of the study solidify, at least in a small way, that Gold Coast law firms are adopting a range of technologies including practice management software, external document storage technologies that increased searchability and mobility of files, document production templates, dictation and voice recognition software and fixed-price billing processes. Under Christensen's definition, most of the respondents were adopting sustaining technologies that maintained the industry's current structure and catered to existing law clientele in a more efficient, economical and automated way. ${ }^{118}$ Although the adoption of technology is undoubtedly changing the practice and expectations of legal professionals, the diffusion process is slow. Charlotta Kronblad and Johanna Pregmark note that, for a true digital transition to take place, a technology must undergo three stages: invention, innovation and diffusion. ${ }^{119}$ Lawyer G and Lawyer E both expressed concerns that they were not taken seriously due to their alternative technological practice, indicating that the use of technology within the legal profession is not currently entirely widespread on the Gold Coast. ${ }^{120}$

Of the technologies discussed with the respondents, practice management software and digital document storage were the most used technologies with seven of the nine respondents using them. Practice management software not only altered the way lawyers managed their cases, but the software also supported a move to fixed-price services for two respondents. Many commentators have been critical of time billing in the legal profession, ${ }^{121}$ claiming that lawyers are billed for their input rather than their output and that the number of hours spent by a law firm has 'little relation to the value that is brought'. ${ }^{122}$ However, due to client pressure and advances in technology, there are now alternative methods of billing being used in the Australian market including capped pricing, value-based pricing, subscription fees and packaged products. ${ }^{123}$ By using technology to automate document production, as Lawyer $\mathrm{G}$ did, or creating fixed-fee arrangements through identifying the necessary time per task, as Lawyer D did, the findings support a shift towards alternative billing structures.

Adding to the slow dispersal of technology within the legal field are the ethical concerns. The ease with which ethical breaches can occur in a digital, connected world has led to suggestions that technological competency is a de facto part of being a modern

\footnotetext{
${ }^{116}$ Lawyer D (interview, 4 May 2018).

${ }^{117}$ Macquarie Bank, Industry in Transition.

118 Christensen, Innovator's Dilemma, 504

${ }^{119}$ Kronblad, "Beyond Digital Inventions," 126-27, 142.

${ }^{120}$ Lawyer G (interview, 18 May 2018) and Lawyer E (interview, 9 May 2018).

${ }^{121}$ James, "Legal Practice on Time," 62.

${ }^{122}$ Susskind, Tomorrow's Lawyers, 17.

${ }^{123}$ Law Society of New South Wales, Future of Law, 48.
} 
lawyer. ${ }^{124}$ This has been formally recognised by the American Bar Association and numerous US states, which have amended their professional conduct rules to include an ethical duty to keep abreast of relevant technology. ${ }^{125}$ While there are no similar provisions in Australia, it has been suggested that technological competency will become a requirement for a practising certificate for future lawyers in Australia. ${ }^{126}$ Despite the importance placed on technological competency in the face of inadvertent ethical breaches through technology, only Lawyer H expressed any concerns pertaining to the topic. It is unclear from the sample interviews why the ethical dangers of technology in legal practice were not raised beyond Lawyer H's contribution. Lawyer $\mathrm{H}$ was also one of the few respondents who was hesitant about the potential for over-reliance on technology in legal practice. ${ }^{127}$ In contrast, the end goal of some respondents was to use technology to create automated passive income - or 'making money while sleeping' — with these respondents placing their trust in the technological process to render legal documents and services correctly without their input. ${ }^{128}$ Lawyer $\mathrm{H}$ had also admitted that they were sometimes personally 'dragged kicking and screaming' into change, but in the end it had always proven beneficial. The respondent's more resistant attitude towards technology does demonstrate, at least peripherally, the existence of lawyers who are more tradition-bound and resistant to change as theorised in the literature. ${ }^{129}$ Nevertheless, most respondents within the sample were actively welcoming of technology and the new opportunities it could bring to the profession.

\section{Conclusion}

This study has argued that Gold Coast legal practitioners embrace technological change and engage with technology to enhance their practice. Two research questions were developed, and open-ended interviews used, to assess the use of technology by Gold Coast legal practitioners. With respect to the first research question on Gold Coast legal practitioners' current use of technology, this study revealed a diverse range of technological adoption including practice management software, alternative billing structures and digital documentation. The implementation of these technologies presented new opportunities for increased flexibility, efficiency and productivity within the legal sphere. However, challenges of ethics, security, cost and failed software were also identified by participants as barriers to full technological conversion. The second question focused on how Gold Coast legal practitioners believed technology would impact their practice in the future. The findings revealed predominantly positive attitudes towards the future of the legal profession's co-existence with technology albeit with some caveats. Positive aspects that respondents anticipated included forthcoming innovations, ever-evolving accessibility and cultural acceptance of new forms of legal practice by more traditionally minded practitioners. A key concern of respondents was the invasiveness of connectedness, which may tether practitioners to their jobs even during hospital visits and holidays, and the potential to be replaced by algorithmic attorneys following the inability of the human to match the uncanny efficiency of the technological.

Overall, the findings of this study depart from the usual assumptions that the legal profession is resistant to technological change. Instead, it was generally found that these Gold Coast legal practitioners from small and medium-sized firms embrace technology. While some commentators hold cynical views that the legal profession resists change due to a perceived threat to their income or social status, ${ }^{130}$ this research has shown that these practitioners hold the opposite view, seeing technology as a way to work more efficiently and target new markets outside of their geographical areas as the opportunities technology offered outshone its potential challenges.

\footnotetext{
${ }^{124}$ Crews, "E-filing," 82-85. govern the conduct of practising solicitors.

${ }^{126}$ Mezrani, "Opting out of Technology."

${ }^{127}$ Lawyer H (interview, 13 June 2018).

${ }^{128}$ Lawyer D (interview, 4 May 2018) and Lawyer G (interview, 18 May 2018).

${ }^{129}$ Simpson, “Algorithms or Advocacy," 50; Susskind, Tomorrow's Lawyers, 59-61.

130 Jenkins "What Can Information Technology Do," 605.
}

${ }^{125}$ Examples include and are not limited to: American Bar Association, Model Rules of Professional Conduct (at August 2018) r $1.1 \mathrm{cmt}$ [8]; State Bar of Arizona, Rules of Professional Conduct (at 2015) r $1.1 \mathrm{cmt}$ [6]; Superior Court of Kentucky, Rules of Professional Conduct (at 16 July 2013) r $1.1 \mathrm{cmt}$ 'Maintaining Competence'; Supreme Court of Florida, Rules Regulating the Florida Bar (at 17 September 2018) r 4-1.1 cmt 'Legal Knowledge and Skill'; etc. Most US states have an equivalent provision in the relevant rules that 


\section{Bibliography}

\section{Primary Sources}

\section{Cases}

Australian Competition and Consumer Commission v Murray (2002) 121 FCR 428.

Barristers' Board v Marbellup Nominees Pty Ltd [1984] WAR 335.

Cornall v Nagle [1995] 2 VR 188.

Legal Practice Board v Giraudo [2010] WASC 4.

\section{Legislation and Regulations}

ACT Law Society. ACT Legal Profession (Solicitors) Conduct Rules (2015).

American Bar Association. Model Rules of Professional Conduct (at August 2018).

Law Council of Australia. Australian Solicitors Conduct Rules (June 2011).

Law Institute of Victoria. Legal Profession Uniform General Rules (2015).

The Law Society of New South Wales. Legal Profession Uniform Law Australian Solicitors' Conduct Rules (2015).

The Law Society of South Australia. Australian Solicitors Conduct Rules (2015).

Law Society of Western Australia. Legal Profession Conduct Rules (2010).

Legal Profession Act 2007 (Qld).

Privacy Act 1988 (Cth).

Queensland Law Society. Australian Solicitors Conduct Rules (2012).

State Bar of Arizona. Rules of Professional Conduct (at 2015).

Superior Court of Kentucky. Rules of Professional Conduct (at 16 July 2013).

Supreme Court of Florida. Rules Regulating the Florida Bar (at 17 September 2018).

\section{Secondary Sources}

Australian Bureau of Statistics. Australian Statistical Geography Standard (ASGS): Volume 5 - Remoteness Structure, July 2016. Cat. no 1270.0.55.005. Canberra: Australia, 2016.

American Bar Association. Report on the Future of Legal Services in the United States. N.p. American Bar Association, 2017.

Beaton, George. "Who Coined NewLaw?” Remaking Law Firms (blog), 8 August 2018. https://remakinglawfirms.com/who -coined-newlaw/.

Bennett, Steven. “The Ethics of Legal Outsourcing.” Northern Kentucky Law Review 36, no 4 (2009): 479-90.

Canadian Bar Association. The Future of Legal Services in Canada: Trends and Issues. Ottawa: Canadian Bar Association, 2013.

Christensen, Clayton. "Disruptive Innovation.” www.claytonchristensen.com/key-concepts.

- The Innovator's Dilemma: When New Technologies Cause Great Firms to Fail. Boston: Harvard Business Review Press, 1997. Kindle.

Corrs Chambers Westgarth. "Corrs Enters Joint Venture with Beagle to Provide Accessible AI Technology in Australia and New Zealand.” Corrs Chambers Westgarth: News, 25 October 2016. https://corrs.com.au/news/2016/10/corrs-enters-joint -venture-with-beagle-to-provide-accessible-ai-technology-in-australia-and-new-zealand. 
Crews, Kevin. "E-filing from the Local Coffee Shop: A Practical Look into Confidentiality, Technology, and the Practice of Law." Florida Law Journal 87, no 6 (2013): 82-85.

Dolin, Ron and Thomas Buley. "Adaptive Innovation: The Innovator's Dilemma in Big Law." Adaptive Innovation 5, no 2 (2019): 1-4.

Ferguson, Zoe. "Lawyers, Accountants Join List of Workers Who Could Lose Their Jobs to AI, Warns Report." ABC News (Australia), 5 April 2017. www.abc.net.au/news/2017-04-05/artificial-intelligence-taking-lawyer-accountant-analyst-jobs 18415286.

Gilbert + Tobin. "Innovation.” 2018. https://www.gtlaw.com.au/about-us/innovation (page since removed, available from http://web.archive.org/web/20180314001159/https://www.gtlaw.com.au/about-us/innovation).

Gillers, Stephen. “A Profession, If You Can Keep It: How Information Technology and Fading Borders are Reshaping the Law Marketplace and What We Should Do About It.” Hastings Law Journal 63, no 4 (2012): 953-1022.

Gold Coast District Law Association. "Home." http://www.gcdla.com.au.

Guihot, Michael. "New Technology, The Death of the BigLaw Monopoly and the Evolution of the Computer Professional." North Carolina Journal of Law and Technology 20, no 3 (2019): 405-69.

Hart, Caroline. "Sustainable Regional Legal Practice: The Importance of Alliances and the Use of Innovative Information Technology by Legal Practices in Regional, Rural and Remote Queensland.” Deakin Law Review 16, no 1 (2011): 22564.

Hathaway, JoAnn L. "Practice Management Software: A Law Firm Essential.” Michigan Bar Journal 96, no 12 (2017): 4647.

Hunter Headline. "Nexus Law Group Win Major National Award.” Hunter Headline, 28 September 2015. https://www .hunterheadline.com.au/hh/business-news/nexus-law-group-win-major-national-award/.

International Bar Association. Artificial Intelligence and Robotics and their Impact on the Workplace Report. London: International Bar Association, 2017.

James, Colin. "Legal Practice on Time: The Ethical Risk and Inefficiency of the Six-Minute Unit." Alternative Law Journal 42, no 1 (2017): 61-66. https://doi.org/10.1177\%2F1037969X17694786

Jenkins, Johnathan. "What Can Information Technology Do for Law?" Harvard Journal of Law and Technology 21, no 2 (2008): 589-607.

Jones, James W., Anthony E. Davis, Simone Chester and Caroline Hart. "Reforming Lawyer Mobility - Protecting Turf or Serving Clients.” Georgetown Journal of Legal Ethics 30, no 1 (2017): 125-93.

Kane, Charmaine. "Law Council of Australia Raises Concerns about Uberisation of Profession by Technology." ABC News (Australia), 28 September 2018. https://www.abc.net.au/news/2018-09-28/law-council-of-australia-raises-concerns-about -uberisation/10306298.

Kowalski, Mitchell. The Great Legal Reformation: Notes from the Field. Bloomington: iUniverse, 2017.

Kronblad, Charlotta and Johanna E. Pregmark. "Beyond Digital Inventions_-Diffusion of Technology and Organizational Capabilities to Change." In Legal Tech, Smart Contracts and Blockchain, edited by Marcelo Corrales, Mark Fenwick and Helena Haapio, 123-46. Singapore: Springer, 2019.

Lambert, John T., Jr. and Margaret L. Bogle. "Pursuit of the Elusive Antecedents: Action Research Unveils Factors Influencing Technology Adoption by Small Law Firms.” Systemic Practice and Action Research 23, no 3 (2009): $251-67$.

Law Society of England and Wales. Capturing Technological Innovation in Legal Services. London: The Law Society, 2017.

The Law Society of New South Wales. The Future of Law and Innovation in the Profession. Sydney: The Law Society of New South Wales, 2017.

The Legal Forecast. “About The Legal Forecast.” https://thelegalforecast.com/about/.

Lim, Rebecca. "What is a True NewLaw Firm?" Legal Insight, 7 December 2016. http://insight.thomsonreuters.com.au/posts true-newlaw-firm.

Love, James, Stephen Roper and John Bryson. "Openness, Knowledge, Innovation and Growth in UK Business Services". Research Policy 40, no 10 (2011) 1438-52.

Macquarie Bank. An Industry in Transition: 2017 Legal Benchmarking Results. N.p: Macquarie Bank, 2017.

Marcus, Richard. “The Impact of Computers on the Legal Profession: Evolution or Revolution?” Northwestern University Law Review 102, no 4 (2008): 1827-68.

McLeod, John. Qualitative Research in Counselling and Psychotherapy. 2nd ed. London: Sage, 2011.

Meyer, Chris, David Cohen and Sudhir Nair. "Some Have To, and Some Want To: Why Firms Adopt a Post-Industrial Form.” Journal of Management and Governance 21, no 2 (2017): 533-59.

Mezrani, Leanne. "Opting out of Technology No Longer an Option.” Lawyers Weekly, 10 March 2015. https://www lawyersweekly.com.au/news/16247-opting-out-of-technology-no-longer-an-option.

Morgan, Thomas, The Vanishing American Lawyer. New York: Oxford University Press, 2010.

Mossman, Mary. "Lawyers and Family Life: New Directions for the 1990s (Part Two)." Feminist Legal Studies 2 , no 2 (1994): 159-82. https://doi.org/10.1007/BF01105176 
Mundy, Trish. "Engendering Rural Practice." Griffith Law Review 22, no 2 (2013): 481-503. https://doi.org/10.1080/10383441.2013.10854784

Neuman, W. Laurence. Social Research Methods: Qualitative and Quantitative Methods. 7th ed. London: Pearson Education, 2013.

Nexus Law Group. “OpenLaw.” How We Do It. https://nexuslawyers.com.au/how-we-do-it/open-law/

Papadakis, Marianna. “G+T Wants to Use Computers to Cut Lawyers' Work.” Australian Financial Review, 9 June 2016. http:// www.afr.com/business/legal/gt-wants-to-use-computers-to-cut-lawyers-work-20160607-gpd5sv

Pasmore, Bill. Leading Continuous Change: Navigating Churn in the Real World. Oakland: Berrett-Koehler, 2015.

Patty, Anna. "Digital Disruption Expected to Make Legal Services Cheaper." Sydney Morning Herald, 29 March 2017. https://www.smh.com.au/business/workplace/digital-disruption-expected-to-make-legal-services-cheaper-20170327 -gv7fhd.html

Queensland Law Society. "Find a Solicitor." https://services.qls.com.au/Web/FindLegalServices/OnlineReferral.aspx

Reynolds, Glenn. "Small is the New Big Law: Some Thoughts on Technology, Economics, and the Practice of Law". Hofstra Law Review 38, no 1 (2009): 1-12.

Ribstein, Larry. "The Death of Big Law." Wisconsin Law Review, no 3 (2010): 749-815.

Semple, Noel, Russell Pearce and Renee Knake. "A Taxonomy of Lawyer Regulation: How Contrasting Theories of Regulation Explain the Divergent Regulatory Regimes in Australia, England and Wales, and North America." Legal Ethics 16, no 2 (2013): 258-83. https://doi.org/10.5235/1460728X.16.2.258

Shepherd, Stafford. Legal Process Outsourcing (PDF), 28 October 2013. https://www.qls.com.au/files/efbc167a-a4d0-4602 -acab-a442011da24c/131025_Legal_Process_Outsourcing.pdf

Simpson, Brian. "Algorithms or Advocacy: Does the Legal Profession Have a Future in a Digital World?" Information \& Communications Technology Law 25, no 1 (2016): 50-61. https://doi.org/10.1080/13600834.2015.1134144

Smith, Michael. "Threat of Ideas: How to Survive the Innovation Age.” Australian Financial Review, 2-4 January 2015.

Smith, Paul. "Legal Giant Norton Rose Fulbright Teams with LawPath to Lure Start-Up Clients." Australian Financial Review, 19 April 2016. www.afr.com/technology/legal-giant-norton-rose-fulbright-teams-with-lawpath-to-lure-startup -clients-20160407-go0v36.

Stoneman, Paul, Patrick Sturgis and Nick Allum. "Exploring Public Discourses about Emerging Technologies through Statistical Clustering of Open-Ended Survey Questions.” Public Understanding of Science 22, no 7 (2012): 850-68.

Susskind, Richard. The End of Lawyers? Oxford: Oxford University Press, 2008.

- Tomorrow's Lawyers: An Introduction to Your Future. Oxford: Oxford University Press, 2013.

Taylor, Ingmar. "The Paperless Barrister: No Longer an Oxymoron.” The Journal of the NSW Bar Association 86, Summer, (2017): 48.

Thornton, Margaret. “The Flexible Cyborg: Work-Life Balance in Legal Practice.” Sydney Law Review 38, no 1 (2016): 121.

Urbis. National Profile of Solicitors 2016. Urbis: New South Wales, 2016.

. National Profile of Solicitors 2018. Urbis: New South Wales, 2018.

Waye, Vicki, Martie-Louise Verreynne and Jane Knowler. "Innovation in the Australian Legal Profession." International Journal of the Legal Profession 25, no 2 (2018): 213-42. https://doi.org/10.1080/09695958.2017.1359614

Williams, Joan C., Aaron Platt and Jessica Lee. "Disruptive Innovation: New Models of Legal Practice.” Hastings Law Journal 67, no 1 (2015): 1-84. 